\title{
Assessing the utilization of contraceptives among men that are sexually active in Ojuelegba Motor Park, Lagos state, Nigeria
}

\author{
Article by Emmanuel Adewale Ojo \\ School of Public Health, Texila American University, Nigeria. \\ Email: walexy@scientist.com
}

\begin{abstract}
This study assessed the knowledge and utilization of contraceptives as well as possible factors impeding its utilization among sexually active men in Ojuelegba Lagos, Nigeria. More than half of the men (63.1\% )had a good knowledge of contraceptives. Overall attitude showed that only few $(41.5 \%)$ had positive attitude towards the use of contraceptives, while $58.5 \%$ had negative attitude. The overall practice of contraception was $26.7 \%$. Barriers to contraceptive utilization include; cost of buying contraceptives (21.7\% ), it causes pregnancy delay (11.5\% ), not easy to use. (12.9\% ), conflicts with religious belief (21.2\% ), family misconception (10.6\%), search for a male child (5.1\%), wanted more babies (24.4\%), weight gain (5.5\% ), permanent damage in the womb(1.8\% ), don't just like the idea (2.3\% )and being unaware of contraceptives ( $0.5 \%)$.

The various contraceptive methods used by the respondents include; hormonal methods (pills, implant, inject able)(11.5\% ), non-hormonal methods (24\% ), sterilization method (8.3\%), traditional methods(22.1\%), condoms (30.4\% ), while the remaining $13.4 \%$ mistook abortion as a family planning method.

This study showed some associated variables that influenced knowledge and practices of contraception while utilization rate was found to be very poor. A fairly good knowledge was seen, respondents' attitude was below average, while the practices of contraception was very poor. Political will and support should be made available to ensure mass enlightenment and adequate availability of various contraceptive methods in order to encourage attitudinal change towards family planning and contraceptive utilization.
\end{abstract}

Keywords: Contraception, sexually - active men, pregnancy, Nigeria.

\section{Introduction}

Unexpected or unplanned pregnancy poses a major public health challenge in women of reproductive age, especially in developing countries. It has been estimated that of the 210 million pregnancies that occur annually worldwide, about 80 million (38\% ) are unplanned, and 46 million (22\% ) end in abortion ${ }^{1}$. Women with unwanted pregnancies usually settle for abortion and often in an unsafe environment, which consequences are grave and life threatening. This study was conducted to assess knowledge, attitude and practices of contraceptives, and possible factors impeding contraceptive utilization in order to contribute to this important goal for behavioral science research.

\section{Methodology}

A cross sectional descriptive study was carried out in Ojuelegba Motor Park. The study population comprised of all sexually active men that engage in commercial activities, such as drivers, conductors and traders, of age group 18-60. A pre tested interviewer administered questionnaire was used to collate information on the subject. The questionnaire comprises of major variables such as; knowledge, attitude and utilization of contraceptives, as well as other factors affecting the utilization of contraceptives. Participants 'selection was done using a simple random sampling technique until a sample size of 217(out of estimated sample size of 250)was obtained. All eligible consenting men, sampled were interviewed by 4 trained research assistants using the pre tested questionnaire. Each interviewer plus the main 
South American Journal of Public Health

Special Edition May 2016

researcher, interviewed approximately 22 respondents in a day, for 2 days. The data was analyzed, using IBM SPSS statistics 21.

\section{Results}

Table 1: Socio Demographic Characteristics of Respondents

\begin{tabular}{|c|c|c|}
\hline SOCIO-ECONOMIC STATUS & FREQUENCY & PERCENTAGE (\%) \\
\hline AGE GROUP & & \\
\hline $20-30$ & 91 & 41.9 \\
\hline $31-40$ & 62 & 28.5 \\
\hline $41-50$ & 42 & 19.3 \\
\hline $51-72$ & 22 & 10.2 \\
\hline TOTAL & 217 & 100.0 \\
\hline MEAN AGE 35.60 & & \\
\hline EDUCATIONAL STATUS & & \\
\hline Primary & 43 & 19.8 \\
\hline Secondary & 145 & 66.8 \\
\hline Tertiary & 25 & 11.5 \\
\hline None & 4 & 1.8 \\
\hline TOTAL & 217 & 100.0 \\
\hline OCCUPATION & & \\
\hline Bus driver & 163 & 75.1 \\
\hline Bus conductor & 49 & 22.6 \\
\hline Trader & 5 & 2.3 \\
\hline TOTAL & 217 & 100 \\
\hline RELIGION & & \\
\hline Islam & 80 & 36.9 \\
\hline Christianity & 117 & 53.9 \\
\hline Traditional & 20 & 9.2 \\
\hline TOTAL & 217 & 100.0 \\
\hline Tribe & & \\
\hline Yoruba & 140 & 64.5 \\
\hline Igbo & 62 & 28.6 \\
\hline Hausa & 0 & 0.0 \\
\hline Akwaibom & 6 & 2.8 \\
\hline Calabar & 3 & 1.4 \\
\hline Delta & 2 & 0.9 \\
\hline Edo & 2 & 0.9 \\
\hline Efik & 2 & 0.9 \\
\hline Total & 217 & 100.0 \\
\hline Marital status & & \\
\hline Single & 78 & 35.9 \\
\hline Married & 134 & 61.8 \\
\hline Separated & 3 & 1.4 \\
\hline Divorced & 2 & 0.9 \\
\hline Total & 217 & 100.0 \\
\hline Number of wives & & \\
\hline 0 & 81 & 37.3 \\
\hline 1 & 116 & 53.5 \\
\hline 2 & 16 & 7.4 \\
\hline 3 & 4 & 1.8 \\
\hline Total & 217 & 100.0 \\
\hline Number of children & & \\
\hline 0 & 83 & 38.2 \\
\hline
\end{tabular}




\begin{tabular}{|l|l|l|}
$1-3$ & 74 & 34.1 \\
$4-7$ & 51 & 23.5 \\
$8-10$ & 9 & 4.2 \\
\hline
\end{tabular}

Only less than half $(41.9 \%$ )of the respondents fell within age group 20-30, which was followed by age group $31-40$ (28.5)\% , with a mean age of 35.61 , and majority (66.8\% )had only secondary education. Almost (75.1\% )all the respondents were bus drivers, while others were bus conductors (22.6\% )and traders (2.3\% ). Majority (53.9\% )were Christians while $36.9 \%$ were Muslims and 9.2\% were Traditionalists. Of all the tribes, majority (64.5\% )were Yoruba. Majority (61.8\% )were married. Most (53.5\% )had only one wife, 38.2\% had no children, while $34.1 \%$ had about one to three children, $23.5 \%$ had four to seven children and only $4.2 \%$ had eight to ten children.

Table 2: Sexual Practice of Respondents

\begin{tabular}{|l|l|l|}
\hline & FREQUENCY & $\begin{array}{l}\text { PERCENTAGE } \\
\mathbf{( \% )}\end{array}$ \\
\hline SEXUALLY ACTIVE & & \\
Yes & 212 & 97.7 \\
No & 5 & 2.3 \\
TOTAL & 217 & 100.0 \\
THOSE THAT RESULTED INTO PREGNANCY & & \\
Yes & 156 & 71.9 \\
No & 56 & 25.8 \\
Don't know & 5 & 2.3 \\
Total & 217 & 100.0 \\
WHY RESPONDENTS' SEXUAL INTER & & \\
COURSE DID NOT LEAD TO PREGNANCY & 96 & 44.2 \\
Condom use & 1 & 0.5 \\
Just didn't lead to pregnancy & 10 & 4.6 \\
Use of pills & 6 & 2.8 \\
Withdrawal method & 104 & 47.9 \\
Not given & 217 & 100.0 \\
TOTAL & & \\
\hline
\end{tabular}

Almost (97.7\% )all of the respondents were sexually active, and $71.9 \%$ claimed that it led to pregnancy, and majority reported condom as their means of preventing pregnancy.

Table 3: Respondents' Knowledge of Contraceptives

\begin{tabular}{|l|l|l|}
\hline & FREQUENCY & $\begin{array}{l}\text { PERCENTAGE } \\
\text { (\%) }\end{array}$ \\
\hline HEARD OF CONTRACEPTIVES & \\
Yes & 131 & 39.6 \\
No & 86 & 60.4 \\
Total & 217 & 100.0 \\
CONTRACEPTIVES ARE USED FOR FAMILY & & \\
PLANNING & 158 & 72.8 \\
Yes & 40 & 18.4 \\
No & 19 & 8.8 \\
Don't know & 217 & 100.0 \\
Total & & \\
USED PREVENT PREGNANCY & 124 & 57.1 \\
Yes & 75 & 34.6 \\
No & 18 & 8.3 \\
Don't know & & \\
\hline
\end{tabular}


South American Journal of Public Health

Special Edition May 2016

\begin{tabular}{|l|l|l|}
\hline Total & 217 & 100.0 \\
USED TO TERMINATE PREGNANCY & 110 & 50.7 \\
Yes & 89 & 41.0 \\
No & 18 & 8.3 \\
Don't know & 217 & 100.0 \\
Total & & \\
CAN CAUSE PERMANENT INFERTILITY & 127 & 58.5 \\
Yes & 71 & 32.7 \\
No & 19 & 8.8 \\
Don't know & 217 & 100.0 \\
Total & & \\
ABORTION IS ANOTHER MEANS OF FAMILY & & \\
PLANNING & 101 & 74.2 \\
Yes & 99 & 18.4 \\
No & 17 & 7.4 \\
Don't know & 217 & 100.0 \\
Total & & \\
\hline
\end{tabular}

Only $60.4 \%$ of the respondents had heard of contraceptives, while $72.8 \%$ agreed that contraceptives are used for family planning. Half (57.1\% )of the respondents agreed that contraceptives are used to prevent pregnancy, while about average $(50.7 \%$ )agreed it is used to terminate pregnancy, more than average $(58.5 \%$ )claimed that it can cause permanent infertility if used by a woman and majority $(74.2 \%$ )claimed that abortion is another means of family planning.

Table 4: Overall Level of Knowledge of Respondents on Contraceptives

\begin{tabular}{|l|l|l|}
\hline & FREQUENCY & PERCENTAGE (\%) \\
\hline GOOD & 137 & 63.1 \\
POOR & 80 & 36.9 \\
TOTAL & 217 & 100.0 \\
\hline
\end{tabular}

More than half (63.1 \% )of the respondents had good overall knowledge on contraceptives, while only $36.9 \%$ had poor overall knowledge on contraceptives.

Table 5: Respondents' Attitude towards Contraceptives

\begin{tabular}{|l|l|l|}
\hline & FREQUENCY & $\begin{array}{l}\text { PERCENTAGE } \\
(\%)\end{array}$ \\
\hline CONTRACEPTIVES GENERALLY HAVE & & \\
NEGATIVE SIDE EFFECTS & 132 & 60.8 \\
Agree & 5 & 2.3 \\
Disagree & 80 & 36.9 \\
Indifferent & 217 & 100.0 \\
Total & & \\
CAUSES WEIGHT GAIN AND STOMACH & & \\
BLOATING & 132 & 60.8 \\
Agree & 24 & 11.1 \\
Disagree & 61 & 28.1 \\
Indifferent & 217 & 100.0 \\
Total & & \\
IT CAUSES INFERTILITY & 63 & 29.0 \\
Agree & 62 & 28.6 \\
Disagree & 92 & 42.4 \\
Indifferent & 217 & 100.0 \\
Total & & \\
\hline
\end{tabular}




\begin{tabular}{|c|c|c|}
\hline IT CAUSES PAINS & & \\
\hline Agree & 88 & 40.6 \\
\hline Disagree & 28 & 12.9 \\
\hline Indifferent & 101 & 46.5 \\
\hline Total & 217 & 100.0 \\
\hline EFFECTIVE FOR FAMILY PLANNING & & \\
\hline Agree & 91 & 41.9 \\
\hline Disagree & 57 & 26.3 \\
\hline Indifferent & 69 & 31.8 \\
\hline Total & 217 & 100.0 \\
\hline $\begin{array}{l}\text { IT'S A BETTER PREVENTION AGAINST } \\
\text { UNWANTED PREGNANCY }\end{array}$ & & \\
\hline $\begin{array}{l}\text { UNWANTED PREGNANCY } \\
\text { Agree }\end{array}$ & 78 & 35.9 \\
\hline Disagree & 64 & 29.5 \\
\hline Indifferent & 75 & 34.6 \\
\hline Total & 217 & 100.0 \\
\hline $\begin{array}{l}\text { REDUCES MATERNAL AND INFANT } \\
\text { MORTALITY }\end{array}$ & & \\
\hline Agree & 96 & 44.2 \\
\hline Disagree & 33 & 15.2 \\
\hline Indifferent & 88 & 40.6 \\
\hline Total & 217 & 100.0 \\
\hline WILLING TO USE CONTRACEPTIVES & & \\
\hline Agree & 90 & 41.5 \\
\hline Disagree & 44 & 20.3 \\
\hline Indifferent & 83 & 38.2 \\
\hline Total & 217 & 100.0 \\
\hline CONTRACEPTIVES ARE EXPENSIVE TO USE & & \\
\hline Agree & 101 & 46.5 \\
\hline Disagree & 52 & 24.0 \\
\hline Indifferent & 64 & 29.5 \\
\hline Total & 217 & 100.0 \\
\hline $\begin{array}{l}\text { WOMEN SHOULD BE ENCOURAGED TO USE } \\
\text { IT }\end{array}$ & & \\
\hline Agree & 91 & 41.9 \\
\hline Disagree & 73 & 33.6 \\
\hline Indifferent & 53 & 24.4 \\
\hline Total & 217 & 100.0 \\
\hline
\end{tabular}

Majority (60.8\% )agreed that contraceptives generally have negative side effects while $60.8 \%$ claimed that it causes general weight gain as well as bloating of the stomach. Few $(29.0 \%)$ agreed that it causes infertility, while majority $(42.4 \%)$ where indifferent about that. $40.6 \%$ agreed that it causes pains, while almost half (46.5\% )were indifferent about it as well. Most (41.9\% )agreed that it is effective for family planning. Only $35.9 \%$ agreed that it is a better prevention means against unwanted pregnancy while $29.5 \%$ disagreed and $34.6 \%$ were indifferent about it. Not up to average (44.2\% )agreed that contraceptive use reduces maternal and infant mortality, but only $15.2 \%$ disagreed and $40.6 \%$ were indifferent about it. Most (41.5\% )were willing to use contraceptives, while few (20.3\% )disagreed. Many (46.5\% )agreed that contraceptives are expensive to use while few (24.0\% )disagreed. $41.9 \%$ agreed that women should be encouraged to use it for family planning, while $33.6 \%$ disagreed, and $24.4 \%$ were indifferent about it. 
South American Journal of Public Health

Special Edition May 2016

Table 6: Overall Attitude of Respondents towards Contraceptives

\begin{tabular}{|l|l|l|}
\hline & FREQUENCY & PERCENTAGE (\%) \\
\hline NEGATIVE & 127 & 58.5 \\
POSITIVE & 90 & 41.5 \\
TOTAL & 217 & 100.0 \\
\hline
\end{tabular}

Majority (58.5\% )had negative attitude towards contraceptives, while only $41.5 \%$ had positive attitude towards contraceptives.

Table 7: Reasons why Respondents did not support Contraceptive Use

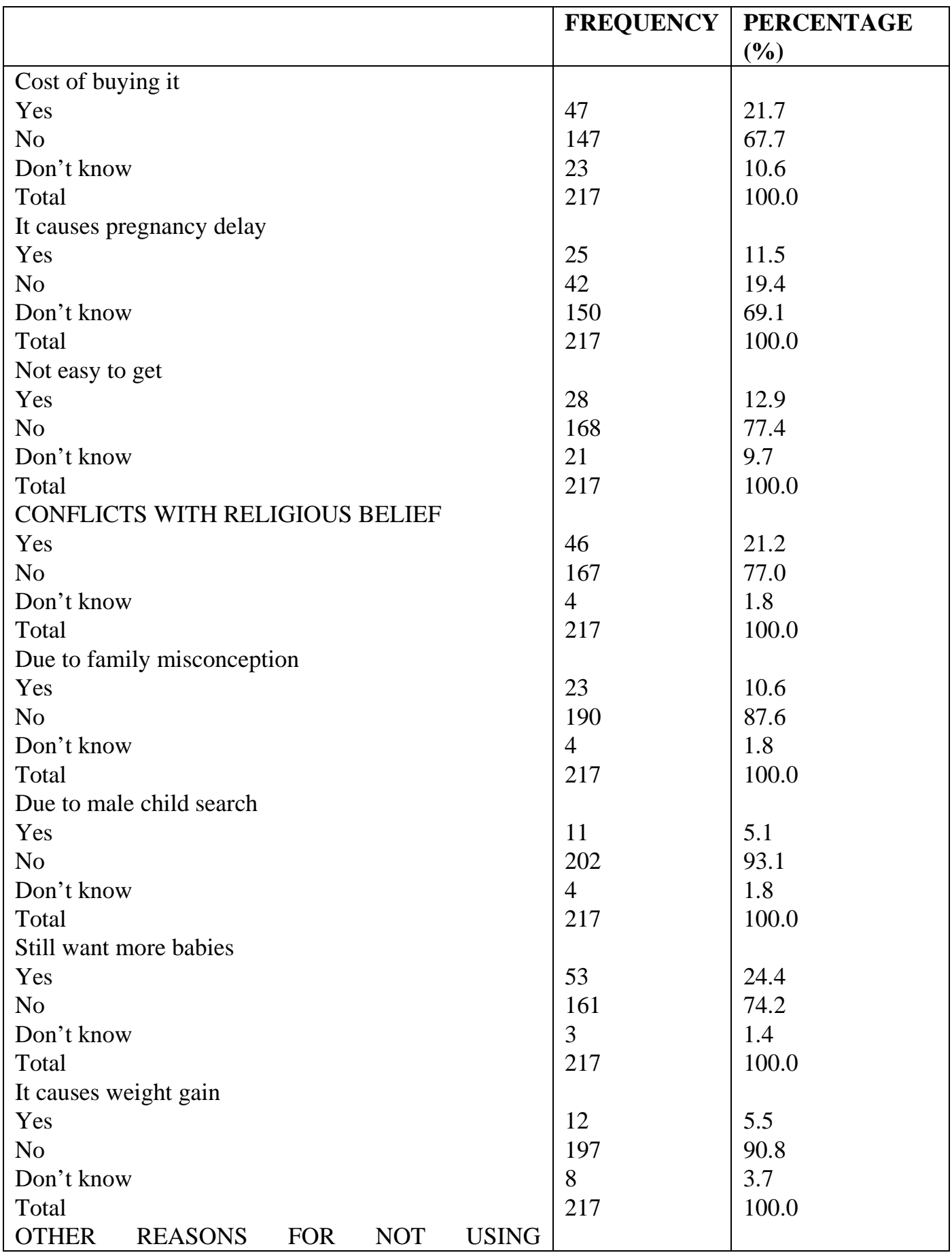


CONTRACEPTIVES

Can cause a permanent damage in the womb of 4 women due to persistent use of pills

Don't just like the idea of using it

Never heard of it

Not given

Total

1.8
2.3
0.5
95.4
100.0

1.8

\begin{tabular}{l|l}
5 & 2.3 \\
1 & 0.5
\end{tabular}

$1 \quad 0.5$

207

217

100.0

Table 8: Practices of Contraceptives amongst Respondents

\begin{tabular}{|l|l|l|}
\hline & FREQUENCY & PERCENTAGE (\%) \\
\hline IF THEY USE CONTRACEPTIVES & & \\
Yes & 58 & 26.7 \\
No & 159 & 73.3 \\
Total & 217 & 100.0 \\
How often they use it & & \\
Always & 32 & 14.3 \\
Sometimes & 26 & 12.4 \\
Never & 159 & 73.3 \\
Total & 217 & 100.0 \\
\hline
\end{tabular}

Only few (26.7\% )reported to use contraceptives, while majority claimed not to use it. Out of the $26.7 \%$ that use contraceptives, $14.3 \%$ claimed to use it always, while $12.4 \%$ reported to use it sometimes, while $73.3 \%$ reported to have never used it.

Table 9: Over all Practice of Contraceptive Utilization

\begin{tabular}{|l|l|l|}
\hline & FREQUENCY & PERCENTAGE (\%) \\
\hline GOOD & 58 & 26.7 \\
POOR & 159 & 73.3 \\
TOTAL & 217 & 100.0 \\
\hline
\end{tabular}

Majority (73.3\% )had poor practices of contraceptives utilization, while only few (26.7\% ) had good practices of contraceptive utilization.

Table 10: Barriers to Contraceptive Utilization

\begin{tabular}{|l|l|l|}
\hline & FREQUENCY & $\begin{array}{l}\text { PERCENTAGE } \\
(\mathbf{\%})\end{array}$ \\
\hline Cost of buying contraceptives & & \\
Yes & 47 & 21.7 \\
No & 147 & 67.7 \\
Don't know & 23 & 10.6 \\
Total & 217 & 100.0 \\
It causes pregnancy delay & & \\
Yes & 25 & 11.5 \\
No & 42 & 19.4 \\
Don't know & 150 & 69.1 \\
Total & 21.7 & 100.0 \\
Not easy to get & & \\
Yes & 28 & 12.9 \\
No & 168 & 77.4 \\
Don't know & 21 & 9.7 \\
Total & 217 & 100.0 \\
Conflicts with religious belief & & \\
Yes & 46 & 21.2 \\
No & 167 & 77.0 \\
\hline
\end{tabular}


South American Journal of Public Health

Special Edition May 2016

\begin{tabular}{|l|l|l|}
\hline Don't know & 4 & 1.8 \\
Total & 217 & 100.0 \\
Family misconception & & \\
Yes & 23 & 10.6 \\
No & 190 & 87.6 \\
Don't know & 4 & 1.8 \\
Total & 217 & 100.0 \\
Searching for male child & & \\
Yes & 11 & 5.1 \\
No & 202 & 93.1 \\
Don't know & 4 & 1.8 \\
Total & 217 & 100.0 \\
Still want more babies & & \\
Yes & 53 & 24.4 \\
No & 161 & 74.2 \\
Don't know & 3 & 1.4 \\
Total & 217 & 100.0 \\
It causes weight gain & & \\
Yes & 12 & 5.5 \\
No & 197 & 90.8 \\
Don't know & 8 & 3.7 \\
Total & 217 & 100.0 \\
Other reasons & & \\
Can cause a permanent damage in women's womb & 4 & 1.8 \\
due to persistent use of pills & & \\
Don't just like the idea of using it & 5 & 2.3 \\
Never heard of it & 1 & 0.5 \\
Not applicable & 207 & 95.4 \\
Total & 217 & 100.0 \\
\hline
\end{tabular}

$21.7 \%$ of the respondents claimed that the cost of buying contraceptives was one of the barriers of contraceptive utilization, while $11.5 \%$ agreed that it causes pregnancy delay, few (12.9\% ) reported it not being easy to get, $21.2 \%$ agreed that it conflicts with their religious belief, while only $10.6 \%$ supported due to family misconception as their major barrier. Just $5.1 \%$ reported search of a male child as their barrier, while $24.4 \%$ still wanted more babies. Only 5.5\% agreed that it is because it causes weight gain. Other reasons mentioned by respondents as their barriers to contraceptive utilization included; it causing permanent damage in their womb, due to persistent use of the pills, $(1.8 \%$ ), while $2.3 \%$ said they don't just like the idea of using it, and $0.5 \%$ said it was because they were unaware of it.

Table 11: Family Planning Methods Used by Respondents

\begin{tabular}{|l|l|l|}
\hline & FREQUENCY & PERCENTAGE \\
\hline Hormonal methods & & \\
Yes & 25 & 11.5 \\
No & 192 & 88.5 \\
Total & 217 & 100.0 \\
Non Hormonal & & \\
Yes & 53 & 24.4 \\
No & 164 & 75.6 \\
Total & 217 & 100.0 \\
Sterilization method & & \\
Yes & 18 & 8.3 \\
No & 199 & 91.7 \\
Total & 217 & 100.0 \\
\hline
\end{tabular}




\begin{tabular}{|l|l|l|}
\hline Traditional methods & 48 & \\
Yes & 169 & 22.1 \\
No & 217 & 77.9 \\
Total & 66 & 100.0 \\
Condom & 151 & 30.4 \\
Yes & 217 & 69.6 \\
No & 100.0 \\
Total & & \\
Those that used abortion as their family planning & & \\
method & 29 & 13.4 \\
Yes & 188 & 86.6 \\
No & 217 & 100.0 \\
Total & & \\
\hline
\end{tabular}

Very few $(11.5 \%)$, respondents used hormonal methods, $24 \%$ used non hormonal methods, only $8.3 \%$ reported to use sterilization, few ( $22.1 \%$ )used the traditional methods, about $30.4 \%$ used condom, while $13.4 \%$ believed and used abortion as their own family planning.

Table 12: Associations between Socio-Demographic Characteristics And Level of Knowledge, Attitude and Practices.

\begin{tabular}{|l|l|l|l|}
\hline SOCIO-DEMOGRAPHIC & $\begin{array}{l}\text { KNOWLEDGE } \\
\text { CHARACTERISTICS }\end{array}$ & $\begin{array}{l}\text { ATTITUDE } X^{2} \\
\text { value (P value) }\end{array}$ & $\begin{array}{l}\text { PRACTICES } X^{2} \\
\text { value (P value) }\end{array}$ \\
\hline AGE & 35.06 & 21.37 & 28.67 \\
& $\mathbf{0 . 3 2 5}$ & $\mathbf{0 . 9 2 3}$ & $\mathbf{0 . 6 3 6}$ \\
EDUCATIONAL STATUS & 0.261 & 11.27 & 2.245 \\
OCCUPATION & $\mathbf{0 . 9 6 7}$ & $\mathbf{0 . 0 1 0}$ & $\mathbf{0 . 5 2 3}$ \\
& 2.497 & 8.521 & 1.742 \\
RELIGION & $\mathbf{0 . 6 4 5}$ & $\mathbf{0 . 0 7 4}$ & $\mathbf{0 . 7 8 3}$ \\
& 0.790 & 0.166 & 6.332 \\
TRIBE & $\mathbf{0 . 6 7 4}$ & $\mathbf{0 . 9 2 0}$ & $\mathbf{0 . 0 4 2}$ \\
& 8.170 & 2.163 & 3.686 \\
MARITAL STATUS & $\mathbf{0 . 2 2 6}$ & $\mathbf{0 . 9 0 4}$ & $\mathbf{0 . 7 1 9}$ \\
& 3.505 & 3.003 & 1.225 \\
NUMBER OF WIVES & $\mathbf{0 . 3 2 0}$ & $\mathbf{0 . 3 9 0}$ & $\mathbf{0 . 7 4 7}$ \\
& 7.700 & 3.014 & 2.008 \\
NUMBER OF CHILDREN & $\mathbf{0 . 0 5 3 *}$ & $\mathbf{0 . 3 9 0}$ & $\mathbf{0 . 5 7 1}$ \\
& $\mathbf{0 . 8 2 3}$ & 8.926 & 7.260 \\
SEXUALLY ACTIVE & 0.626 & $\mathbf{0 . 5 3 9}$ & $\mathbf{0 . 7 0 1}$ \\
& $\mathbf{0 . 4 2 9}$ & 0.972 & 0.118 \\
\hline
\end{tabular}

Only the number of wives of the respondents was associated with the level of knowledge of the respondents $(\mathbf{X} \mathbf{2}=\mathbf{7 . 7 0 0}, \mathbf{P}$-value $=\mathbf{0 . 0 5 3})$, while the respondents 'education $(X 2=11.27$, Pvalue $=0.010)$ and occupation $(X 2=8.521, P$-value $=0.074)$ were associated with attitude and only respondents 'religion $(\mathbf{X} 2=6.332$, $P$-value=0.042) was associated with their practices of contraceptives.

\section{Discussion and Conclusion}

Proper understanding of the factors associated with contraceptive method choice has been recognized as an important tool for evaluating and improving the quality of reproductive health care. ${ }^{2}$ This study assessed the knowledge, attitude and practices of contraception amongst men that engage in commercial activities in Ojuelegba motor park, Lagos. Out of the 250 estimated sample size, 217 participated in the study. The modal age was 20-30, while 
South American Journal of Public Health

Special Edition May 2016

mean age was 35.60. Of all the tribes, majority (64.5\% )were Yoruba. Majority (66.8\% )had only secondary education, while only $11.5 \%$ had tertiary education. Majority $(75.1 \%$ )were bus drivers, $53.9 \%$ of the respondents were Christians, while 36.9\% were Muslims and 9.2\% were Traditionalists. Majority (61.8\% )were married, which is far less than the study carried out in Ilorin ${ }^{3}$, where almost all (94.8\% )the respondents were married. Most (53.5\% )had only one wife, 38.2\% had no children, while $34.1 \%$ had about one to three children, $23.5 \%$ had four to seven children and only $4.2 \%$ had eight to ten children.

\section{Respondents' knowledge of contraceptives}

Only 39.6\% had heard of contraceptives, which is less than that of North Africa and Asia (90\% ), as well as that of Pakistan, Tanzania and Ghana, with $79 \%, 86 \%$ and $90 \%$ respectively. ${ }^{4}$ In this study, $72.8 \%$ believed it is used for family planning, about average (57.1 $\%$ )agreed it is used to prevent pregnancy, which is higher than that of Ile Ife, with $4.2 \%$ of respondents that agreed that it is used to avoid unwanted pregnancy. $50.7 \%$ says it is used to terminate pregnancy. Most (58.5\% )believed it can cause permanent infertility this study, unlike that carried out in Ile Ife, with $30.5 \%$, while $74.2 \%$ believed abortion is another means of family planning. ${ }^{5}$

\section{Attitude of Respondents towards Contraceptives}

Respondents' attitude towards contraceptive was assessed, using a 3 points likert scale, and majority Most (58.5\% )had negative attitude towards contraceptives, while only $41.5 \%$ had positive attitude towards contraceptives in this study, which is a bit higher than that of Ile Ife, which was $30.5 \%$.5In this study, $60.8 \%$ of the respondents agreed that contraceptive generally have negative side effects, far higher than the $30.5 \%$ of Ife. $60.8 \%$ supported that it causes weight gain and stomach bloating in women, $29.0 \%$ agreed that it can cause infertility, while $40.6 \%$ agreed it causes pains. Most (41.9\% )agreed that it is effective for family planning, while $35.9 \%$ reported that it is the best option against unwanted pregnancy. Many $(44.2 \%$ )supported that it reduces maternal and infant mortality, while less than half $(41.5 \%)$ agreed being willing to use it. $46.5 \%$ claimed that it is expensive to use, and less than half $(41.9 \%$ )agreed that women should be encouraged to use it. Only $21.7 \%$ claimed that it is due to the cost of buying it, while few (11.5\% )reported that it causes pregnancy delay. Very few $(12.9 \%$ )reported that it is not easy to get, while $21.2 \%$ claimed that it conflicts with their religious belief, which is not as much as agreed in Ife, with $44.1 \%$. In this study, $10.6 \%$ agreed that it is due to family misconception, and $5.1 \%$ reported that it was due to their search for male child, which was equally supported in the Tanzanian study. $24.4 \%$ still wanted more babies, which is so close to the $25 \%$ of the study in Tanzania. $5.5 \%$ says because it causes weight gain. (1.8\% )of the respondents mentioned that it can cause a permanent damage in the womb of women that persistently use the pills. Few (2.3\% )just don't like the idea of using it and $0.5 \%$ of them had never heard of It. ${ }^{4}$

\section{Practices of Contraceptives amongst Respondents}

This was determined by asking respondents if they use contraceptives and often they use it. Only $26.7 \%$ had ever used contraceptives, which is lower than $30 \%$ of the study carried out in Ilorin, ${ }^{6}$ but just a little higher than the $18 \%$ of the study of Tanzania, ${ }^{7}$ while $14.3 \%$ claimed that they used it always. Majority claimed to never use it, while only few (12.4\% )reported to use it sometimes.

\section{Barriers to Contraceptive Utilization}

Few $(21.7 \%$ )reported that their major barrier to contraceptive usage was cost of buying contraceptives, while $11.5 \%$ agreed that it causes pregnancy delay, just as reported in the Focus Group Discussion(FGD)done by International Conference on Population Development (ICPD). Few (12.9\% )reported it not being easy to get, 21.2\% agreed that it conflicts with their religious belief, just as reported by the ICPD research (FGD)on African countries, where 
they felt it is biblically wrong to use the modern methods, but rather prefer natural, which has severally proven to fail, 6 while only $10.6 \%$ supported due to family misconception as their major barrier, which was as well stated in a study done in rural central India, where the mother in law disapprove contraceptives use by the son and the daughter in law. ${ }^{9}$ Just $5.1 \%$ reported search for a male child as their barrier, while $24.4 \%$ still wanted more babies, just as stated by $62 \%$ of the respondents in the same rural central India study as reported in the FGD done by ICPD, where they belief that children can easily die, and there might be replacement to take care of the parents. ${ }^{6}$ And only $5.5 \%$ agreed that it is because it causes weight gain. Other reasons mentioned by respondents as their barriers to contraceptive utilization included; it causing permanent damage in their womb, due to persistent use of the pills, $(1.8 \%)$, while $2.3 \%$ said they don't just like the idea of using it, and $0.5 \%$ said it was because they were unaware of it.

\section{Contraceptive methods used by the respondents}

Very few (11.5\% ), respondents used hormonal methods, such as (pills, implant, injectible, etc), while about $13 \%$ reported using pills in the Indian study, $24 \%$ used non hormonal methods, only $8.3 \%$ reported to use sterilization, few (22.1\% )used the traditional methods, which is a bit lower than the $30 \%$ of the same Indian study. ${ }^{10}$ About $30.4 \%$ used condom in this study, which is lower than the $55 \%$ of the study done in India, ${ }^{10}$ while $13.4 \%$ in this study believed and used abortion as their own family planning.

\section{Associations between socio demographic characteristics and knowledge, Attitude and practices.}

Regarding the factors that predict contraceptive use, Only the number of wives of the respondents was associated with the level of knowledge of the respondents $(\mathbf{X} 2=7.700, \mathbf{P}$ value $=\mathbf{0 . 0 5 3}$ ), meaning, those that were polygamous had more knowledge on contraceptives, which could be as a result of their experience with respect to having wives and already having enough children, as well as the advice they get from the health facilities upon child delivery, while the respondents 'education $(X 2=11.27, P$-value $=\mathbf{0 . 0 1 0})$ and occupation $(X 2=8.521$, $P$ value $=\mathbf{0 . 0 7 4}$ ) were associated with attitude, which could be due to their level of knowledge. Only respondents' religion $(\mathbf{X} 2=\mathbf{6 . 3 3 2}$, $\mathbf{P}$-value $=\mathbf{0 . 0 4 2})$ was associated with their practices of contraceptives.

More than half (63.1\% )had a good knowledge of contraceptives. Overall attitude showed that only few $(41.5 \%$ )of the respondents had positive attitude towards the use of contraceptives, while $58.5 \%$ had negative attitude. The overall practice of contraception was $26.7 \%$. This study revealed some barriers to contraceptive utilization, which include; cost of buying contraceptives $(21.7 \%$ ), it causing pregnancy delay (11.5\% ), it not being easy to use. (12.9\% ), conflicts with religious belief (21.2\% ), family misconception (10.6\% ), search for a male child (5.1\% ), wanted more babies (24.4\% ), weight gain (5.5\%), permanent damage in the womb due to persistent use of pills (1.8\% ), don't just like the idea of using contraceptives (2.3\% )and being unaware of contraceptives $(0.5 \%)$.

However, this study showed that some factors affect respondents 'knowledge, attitude and practice of contraceptive utilization. Number of wives of the respondents was associated with the level of knowledge of the respondents $(X 2=7.700, P$-value $=0.053)$, meaning, those that were polygamous had more knowledge on contraceptives, which could be as a result of their experience with respect to having wives and already having enough children, as well as the advice they get from the health facilities upon child delivery, The respondents 'education $(X 2=11.27, P$-value $=0.010)$ and occupation $(X 2=8.521, P$-value $=0.074)$ were associated with attitude, which could be due to their level of knowledge. Only respondents 'religion (X2=6.332, $\mathbf{P}$-value=0.042) was associated with their practices of contraceptives. This could be as a result health tips inculcated into the sermons given during church service. However, age, tribe, marital status, number of children and being sexually active, in this study did not have any association with knowledge, attitude and practices of contraceptives method for 
South American Journal of Public Health

Special Edition May 2016

family planning. Based on the findings of this study, the following recommendations are made, in order to improve the health indices of the nation;

- There is a need for more male targeted information in the mass media, in other to improve their awareness on the need for male involvement and participation.

- Policies and provisions should be made to create an improved social marketing of family planning commodities and make contraceptives easily affordable and accessible to people.

\section{References}

[1.] Abiodun OM, Balogun OR. Sexual activity and contraceptive use among young female students of tertiary educational institution in Ilorin, Nigeria. Contraception. 2009;79:146-149.

[2.] A. I Olugbenga Bello, V. O OBOR O, M. O. Araoye and I. O. Musa Contraceptive practice among intercity drivers in an urban settlement in north central, Nigeria

[3.] Ijadunola M. Y, Ijadunola K. T, Abiona T. C, Esimai O. A, Afolabi O. T Male involvement in family planning decision making in Ile-Ife, Osun State. (Afr J Reprod Health. 2010 Dec; 14(4 Spec no.):43-50.

[4.] International Journal of Tropical Medical. 2009, vol 4: Issue: 2, Page No: 55-58

[5.] Khan Bella M. E, Patel CMale Involvement in family planning A KABP Study of Agra District India final report population council June 1997.

[6.] Moreland, S. and S. Talbird (2006), "Achieving the Millennium Development Goals: The Contribution of Fulfilling the Unmet Need for Family Planning.”Washington, DC: Constella Futures, POLICY Project.

[7.] Singh, S., J. Darroch, M. V lass of, and J. Nadeau. Adding It Up: The Benefits of Investing in Sexual and Reproductive Health Care. New York: UNFPA, 2004

[8.] Tanzania Demographic Health Survey (1996), p 39-90, 140-168. Final report.

[9.] Teresa Castro Martı́n; Contraceptive use patterns among Spanish single youth; The European Journal of Contraception and Reproductive Health Care December 2005;10(4):219- 228.

[10.] WHO, Safe Abortion: Technical and Policy Guidance for Health Systems, World Health Organization, Geneva, Switzerland, 2nd edition, 2012,

http://apps.who.int/iris/bitstream/10665/70914/1/9789241548434_eng.pdf. 